\title{
Coronary ostial plasty using femoral artery patch in Takayasu aortitis: A 15-year follow-up study
}

Kiyotoshi Oishi, MD, ${ }^{\mathrm{a}}$ Hirokuni Arai, MD, PhD, ${ }^{\mathrm{a}}$ and Tetsuya Yoshida, MD, PhD, ${ }^{\mathrm{b}}$ Tokyo and Nagano, Japan

Video clip is available online.

Takayasu aortitis is the cause of noninfectious inflammation with unknown etiology and commonly results vascular luminal narrowing. ${ }^{1}$ Occasionally, aortic wall thickness affects the coronary ostia and causes angina pectoris or acute coronary syndrome. ${ }^{1}$ Previously, we reported on coronary ostial angioplasty with a superficial femoral artery (SFA) patch in Takayasu aortitis. $^{2}$

A 45-year-old woman with Takayasu aortitis experienced angina pectoris and underwent surgical bilateral coronary ostial angioplasty with an SFA patch. Coronary angiography showed localized stenotic lesions of both the right coronary artery and the left coronary artery ostia without any stenotic lesion of the distal coronary artery. A portion of the SFA was harvested longitudinally and incised to make a rectangular patch. The resected portion of SFA was reconstructed with a vascular prosthesis. After transection of the ascending aorta, aortotomy was extended to the roof of the left coronary artery along a straight line. The patch was sutured such that it created a curtain fold that arched over the roof of the coronary artery, thus ensuring a sufficient orifice for the coronary ostium ${ }^{2}$ (Figure 1 and Video 1). A follow-up computed tomography scan, conducted 15 years after surgery showed that both coronary artery ostia were wide in diameter, without calcification or aneurysmal dilatation (Figure 2). The patient remains asymptomatic and requires no further

From the ${ }^{\mathrm{a}}$ Department of Cardiovascular Surgery, Graduate School of Medical and Dental Science, Tokyo Medical and Dental University, Tokyo, Japan; and ${ }^{\mathrm{b}}$ Department of Cardiovascular Surgery, Hokushin General Hospital, Nagano, Japan.

Disclosures: The authors reported no conflicts of interest.

The Journal policy requires editors and reviewers to disclose conflicts of interest and to decline handling or reviewing manuscripts for which they may have a conflict of interest. The editors and reviewers of this article have no conflicts of interest.

Received for publication March 17, 2020; revisions received March 17, 2020; accepted for publication April 2, 2020; available ahead of print April 11, 2020.

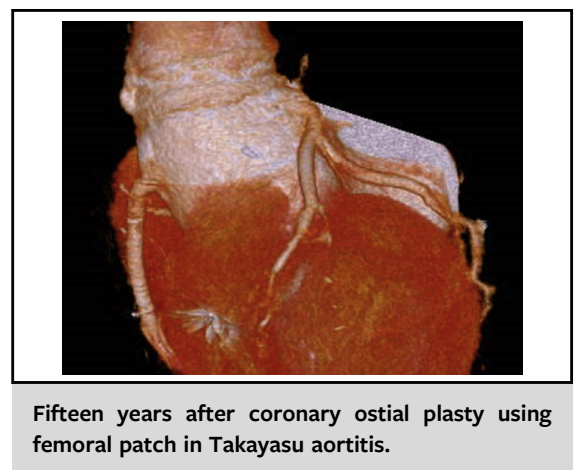

CENTRAL MESSAGE

We report on femoral patch angioplasty for coronary ostial stenosis in Takayasu aortitis. A follow-up coronary CT scan obtained 15 years after surgery showed good long-term patency.

See Commentaries on pages 179 and 181.

intervention. The patient provided informed consent for the publication of the study data.

In Takayasu aortitis, patients are relatively young and coronary artery stenosis is generally limited to the ostium without distal lesion. Moreover, the longterm patency of aortocoronary bypass grafting has been unsatisfactory because of intimal thickening of the aortic wall. ${ }^{3}$ In terms of patch material, saphenous

Address for reprints: Hirokuni Arai, MD, PhD, Department of Cardiovascular Surgery, Graduate School of Medical and Dental Science, Tokyo Medical and Dental University, 1-5-45, Yushima, Bunkyo-ku, Tokyo, 113-8519 Japan (E-mail: hiro. cvsg@tmd.ac.jp).

JTCVS Techniques 2020;3:176-8

2666-2507

Copyright $(2020$ The Authors. Published by Elsevier Inc. on behalf of The American Association for Thoracic Surgery. This is an open access article under the CC BY-NCND license (http://creativecommons.org/licenses/by-nc-nd/4.0/).

https://doi.org/10.1016/j.xjtc.2020.04.006 

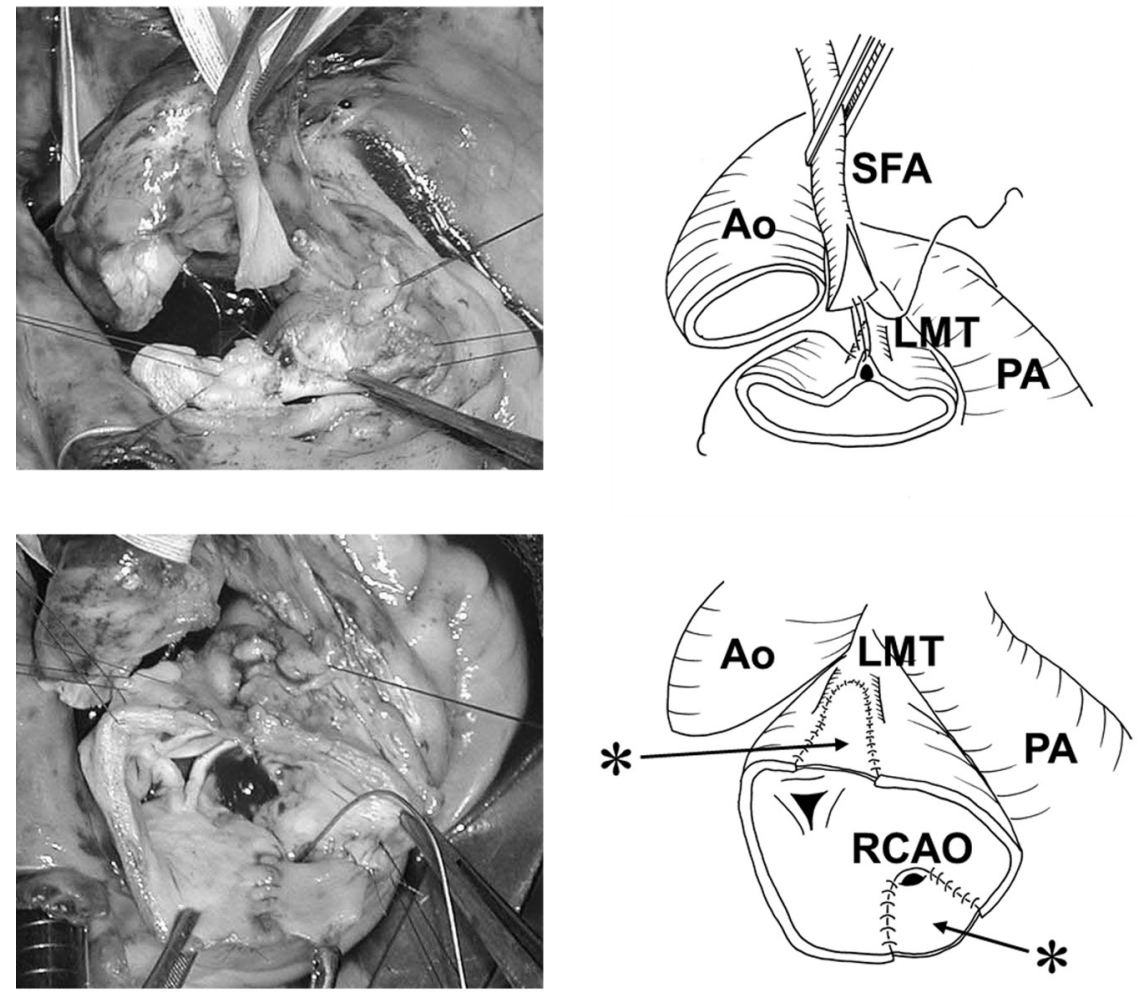

FIGURE 1. Coronary ostial angioplasty with superficial femoral artery ( $S F A)$ patch. Longitudinal incision from the aortotomy down to the coronary artery ostium was made and incised superficial femoral artery was sutured to create a sufficiently enlarged coronary ostium. Asterisk indicates superficial femoral artery patch. Ao, Aorta; $L M T$, left main trunk; $P A$, pulmonary artery; $R C A O$, right coronary artery. Reprinted with permission from Elsevier. ${ }^{2}$

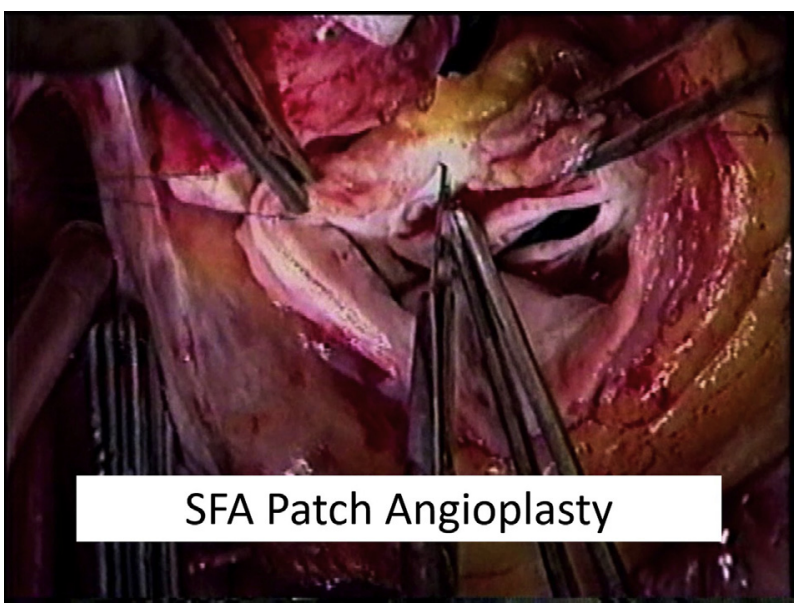

VIDEO 1. Coronary ostial angioplasty with superficial femoral artery (SFA) patch. Longitudinal incision from aortotomy was extended to the coronary artery and rectangular SFA patch was sutured to create a sufficiently enlarged orifice of the coronary artery. Postoperative coronary angiography showed an enlarged coronary ostium. Video available at: https:// www.jtcvs.org/article/S2666-2507(20)30195-4/fulltext. vein, pericardium, pulmonary artery, or internal thoracic artery has been used for coronary ostial plasty, although these patch materials and their longterm efficacy are debated. ${ }^{4}$ The SFA is usually free from inflammation and it is easy to manage because it possesses adequate tissue affinity for the thickened aortic wall. Furthermore, a long-term solution was desirable in the present case. The superficial femoral artery could potentially be an ideal patch material for coronary ostial plasty in Takayasu aortitis.

\section{References}

1. Gornik HL, Creager MA. Aortitis. Circulation. 2008;117:3039-51.

2. Arai H, Yoshida T, Hasegawa S, Sunamori M. Bilateral surgical coronary ostial angioplasty with a superficial femoral artery patch in Takayasu aortitis. J Thorac Cardiovasc Surg. 2002;124:845-7.

3. Endo M, Tomizawa Y, Nishida H, Aomi S, Nakazawa M, Tsurumi Y et al. Angiographic findings and surgical treatments of coronary artery involvement in Takayasu arteritis. J Thorac Cardiovasc Surg. 2003;125: $570-7$.

4. Harling L, Sepehripour AH, Ashrafian H, Lane T, Jarral O, Chikwe J, et al. Surgical patch angioplasty of the left main coronary artery. Eur J Cardiothorac Surg. 2012;42:719-27. 

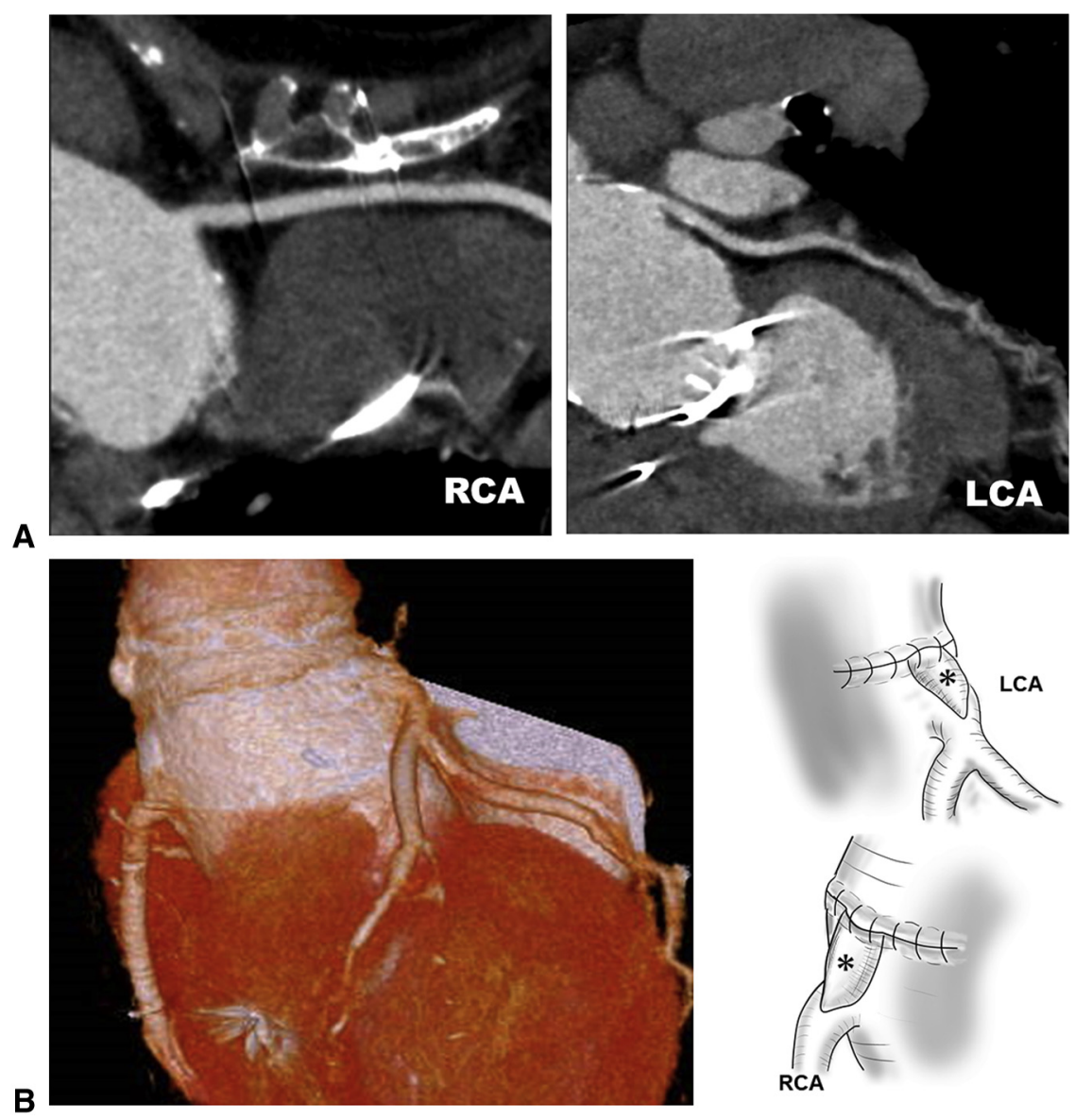

FIGURE 2. Computed tomography images obtained 15 years after surgery, during follow-up. A, Longitudinal views through the coronary ostia showing wide diameter. B, Three-dimensional reconstruction image indicating patency of the coronary ostium without calcification or aneurysmal dilatation. $L C A$, Left coronary artery; $R C A$, right coronary artery. *Superficial femoral artery patch. 